\title{
The assessment of the frequency and arrangement of the subsegmental branches of V3 using computed tomography angiography
}

\author{
Kai Liu ${ }^{1}$, Xinli Liu ${ }^{2}$, Huixiao Song ${ }^{3}$, Xiujuan Gao ${ }^{4}$, Menglong Zhang ${ }^{5}$, Yuangang Qi ${ }^{6}$ \\ ${ }^{1}$ Department of Medical Imaging, Ganzhou People's Hospital, The Affiliated Ganzhou Hospital of Nanchang University, Ganzhou, China; \\ ${ }^{2}$ Department of Radiology, The Forth People's Hospital of Jinan, Jinan, China; ${ }^{3}$ Department of Traditional Chinese Medicine, Ganzhou People's \\ Hospital, The Affiliated Ganzhou Hospital of Nanchang University, Ganzhou, China; ${ }^{4}$ Department of Cardiology, Ji'nan Jigang Hospital, Jinan, \\ China; ${ }^{5}$ Department of Minimally Invasive Intervention, Ganzhou People's Hospital, The Affiliated Ganzhou Hospital of Nanchang University, \\ Ganzhou, China; 'Department of Radiology, Shandong Cancer Hospital and Institute, Shandong First Medical University and Shandong Academy \\ of Medical Science, Jinan, China
}

Correspondence to: Yuangang Qi, MD. Department of Radiology, Shandong Cancer Hospital and Institute, Shandong First Medical University and Shandong Academy of Medical Science, Jinan 250117, China. Email: qiyuangang2004@126.com.

Background: The frequency and arrangement of the subsegmental branches of the third portion of the vertebral artery (V3) have been assessed in small samples by autopsy, but they have not been assessed by computed tomography angiography (CTA). To determine the frequency and arrangement of subsegmental branches of V3 by CTA and to analyze the interrelationships among frequency, arrangement, sex, and side-to-side.

Methods: First, the radiology records of 668 consecutive patients who underwent cervical or craniocervical CTA scans from October 1, 2017 to October 31, 2019 were retrospectively retrieved. Second, the four demarcation points were ascertained to define the three subsegments by reviewing the resource images, namely, the vertical portion of V3(V3v), horizontal portion of V3(V3h), and extradural portion of V3(V3e). Then, the numerical value and the location of the bifurcating branch in each subsegment of V3 were recorded. Third, the frequency and arrangement of the branches was assessed, and the relationships between sex, laterality and frequency and arrangement were analyzed as well as the interobserver performance.

Results: On the left, $25 \%, 20.21 \%$, and $6.59 \%$ were the frequencies of one branch in the V3v, V $3 \mathrm{~h}$, and $\mathrm{V} 3 \mathrm{e}$, and $1.05 \%, 0.00 \%$, and $0.45 \%$ were the frequencies of two branches, respectively. On the right, $25.04 \%, 17.07 \%$, and $6.44 \%$ were the frequencies of one branch in the V3v, V3h, and V3e, and $1.04 \%$, $0.3 \%$, and $0.15 \%$ were the frequencies of two branches, respectively. There were no differences between the side-to-side and numerical values of the branches according to the t-test $(\mathrm{P}=0.4341, \mathrm{P}=0.7968)$, and there were no differences between the side-to-side variable, sex variable and number of branches according to the $t$-test $(\mathrm{P}=0.4474, \mathrm{P}=0.3593)$. There were no differences between the side-to-side and eight arrangements (permutation of $000 ; 100 ; 110 ; 111 ; 010 ; 011 ; 001 ; 101)$ by using the two-sample KS test $(\mathrm{P}=0.942)$, and there were no differences between sex and the eight arrangements according to the two-sample KS test $(\mathrm{P}=0.9973$, $\mathrm{P}=0.8519)$. The interobserver reliability was excellent (Spearman's ranked correlation: 0.9927).

Conclusions: The frequency and arrangement of V3 subsegmental branches could be displayed by source imaging with CTA, and there were no significant differences according to the sex or side of the individual. It was imperative to acquaint the subsegmental branches before the operation involving V3 in the craniocervical junction to determine the surgical approach and reduce bleeding during the surgical procedures.

Keywords: V3; branch; computed tomography angiography; frequency; arrangement

Submitted Jun 04, 2020. Accepted for publication Oct 18, 2020.

doi: 10.21037/qims-20-725

View this article at: http://dx.doi.org/10.21037/qims-20-725 


\section{Introduction}

The V3 is located within the craniocervical junction; it originates from the transverse foramen of the axis, continues inferiorly with the second portion of the vertebral artery (V2), reaches the piercing site of the dura mater at the foramen magnum, and continues superiorly with the fourth portion of the vertebral artery (V4). Many vascular lesions in V3, including tumors, occlusions, deformities, and those caused by trauma, have been documented, and these lesions have been associated with dissection, aneurysm, and Bow Hunter Syndrome (1-5). The decision of whether to utilize or to protect V3 varies by the disease during treatment (6-13). To date, many imaging modalities, such as digital subtraction angiography, dualenergy computed tomography, Doppler ultrasound, and MRI, have be applied to detect V3 (14-18). CTA has been frequently in imaging examinations to simultaneously reveal the three-dimensional anatomy surrounding V3, as it has the advantages of being noninvasive and fast and yielding volumetric scans. Morphometric analyses of V3 performed by using CTA have been reported in many studies (19-24), but the branches of V3 have been studied in few studies, with small sample sizes of cadavers due to the high cost and intricate procedures required (25-27). Although a large sample of vertebral arteries can be assessed by CTA, the branches of $\mathrm{V} 3$ have not yet been reported. The purpose of this study was to reveal the frequency and arrangement of the subsegmental branches of V3 on CTA source images in a large sample, analyze the relationships of these data with the patient's sex and laterality, and evaluate interobserver performance.

\section{Methods}

The retrospective study was approved by the institutional review board, and informed consent was waived.

\section{Patients}

Using radiology computer records, we retrospectively identified 668 consecutive domestic patients of Han nationality in the People's Republic of China who had undergone a cervical or cervical or craniocervical CTA scan from October 1, 2017 to October 31, 2019. The CTA scans were collected from a large referral base in a major tertiary care Chinese university hospital, Shandong Medical Imaging Research affiliated with Shandong University in the People's Republic of China. The mean age of the patients was 55.8 years (age range, 2.9-84.6 years). The patients included 419 men and 249 women (Table 1). The inclusion criteria of the study were as follows: (I) patients who were clinically diagnosed with cervical vascular lesions and underwent CTA scans so that the disease nature, location, and extent could be assessed; (II) patients who had no contraindications to CTA, such as a high temperature, heart failure, or kidney failure; and (III) patients whose V3 coursed normally. In other words, some vertebral artery anomalies were included in our study, such as a highriding vertebral arteries, posterior cerebellar arteries with extracranial atlas/axial (C1/2) origins, and persistent first intersegmental arteries because of the normal course of V3. Thirty-one patients were excluded for the following reasons: 19 cases were accompanied by congenital osseous deformities and dislocation in the craniocervical junction (12 cases of basilar invagination, 7 cases of assimilation of the atlas), 5 cases were occluded in V3 bilaterally, and 1 case had a bilaterally fenestrated vertebral artery. Six patients had abnormally enhanced surrounding veins, including 2 cases of neoplastic lesions.

\section{Acquisition of CTA images}

The patients were placed in a supine position with their arms placed alongside the body and the head and neck in a neutral position. For each patient, a CTA scan was performed using a dual-source CT scanner (Somatom Definition Flash CT VA48A, Siemens Medical Solutions, Forchheim, Germany) with the following parameters: $150 \mathrm{kV}, 51 \mathrm{mAs} ; 100 \mathrm{kV}, 87 \mathrm{mAs}$; collimation of $2 \times 128 \times$ $0.6 \mathrm{~mm} ; 250 \mathrm{~ms} /$ rotation; and a pitch of 0.85 . A contrast medium bolus (Iohexol, $350 \mathrm{mg}$ of iodine per milliliter) with an automatic trigger sequence was utilized for cervical arterial angiography (ascending aorta $100 \mathrm{HU}$ ). During the procedure, $45 \mathrm{~mL}$ of nonionic iodinated contrast medium, followed by $40 \mathrm{~mL}$ of saline, was infused and injected via a double power injector into the patient's antecubital vein at a rate of $5 \mathrm{~mL} / \mathrm{s}$. A pediatric sedative (chloral hydrate, $0.5 \mathrm{~mL} / \mathrm{kg}$ ), if necessary, was taken orally by the infants. The dosage of contrast medium was reduced in proportion to the infants' weight, and infant scanning parameters were selected accordingly. All the data were exported to a workstation (Syngo.via software (Syngo.via VB20A HF06 Siemens Healthineers). The source images were viewed randomly using multiplanar reconstruction with a thickness of less than $1 \mathrm{~mm}$. 
Table 1 The patient characteristics

\begin{tabular}{lccc}
\hline & & Age $(\mathrm{y})$ & \\
\cline { 2 - 4 } Number of cases & Minimum & Maximum & Mean \pm standard deviation \\
\hline Total: 668 & 2.9 & 84.6 & $55.8 \pm 13.0$ \\
Males: 419 & 2.9 & 84.6 & $55.6 \pm 13.0$ \\
Females: 249 & 18.6 & 83.2 & $56.1 \pm 13.0$ \\
\hline
\end{tabular}

A

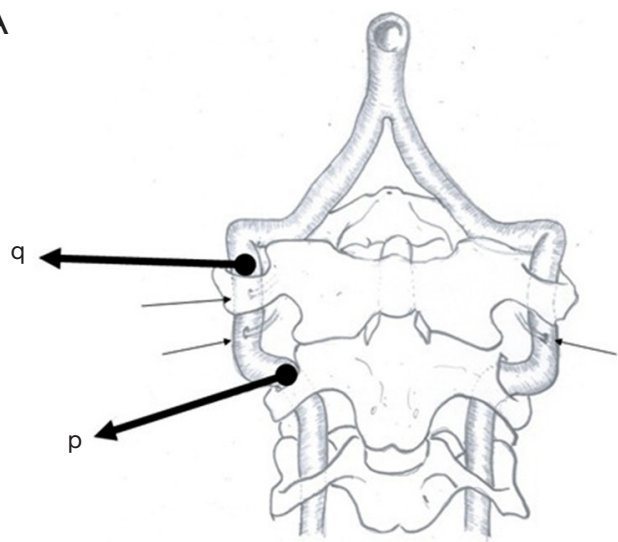

B

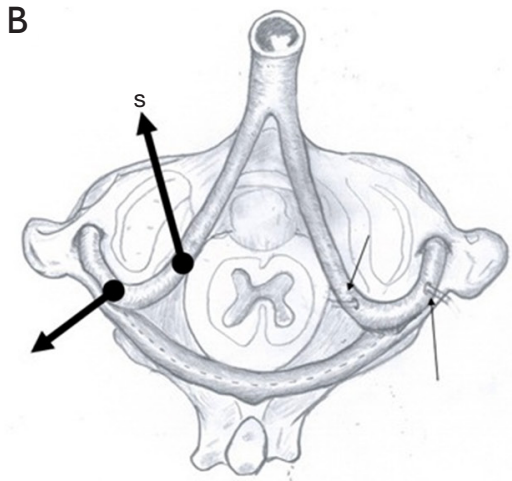

Figure 1 Schematic drawing of the demarcation of three subsegments of V3 and examples of the arrangements of the branches of V3 in the same patient. (A) The point "p" is located at the superior border of the foramen of left C2, and the point "q" is located at the superior border of the foramen of left C1. The V3v was the vertebral artery of V3 between "p" and "q". (B) The point " $\mathrm{r}$ " was located at the point of intersection of the course of $\mathrm{V} 3$ and the superior border of the left $\mathrm{C} 1$, to which the posterior atlantooccipital membrane was attached, and the point "s" was the site of the dura pierced by the left V3. The V3h was the vertebral artery of V3 located between "q" and "r", and V3e was located between "r" and "s". (A,B) Two branches sprouted from V3v on the right (small arrow), and there was one branch on the left. One branch sprouted from V3h and V3e on the left (small arrow). (1,0,0) is the arrangement of V3 in the left, and $(1,1,1)$ is the arrangement on the right.

\section{Image analysis}

All the images were reviewed in consensus by three radiologists, each of whom had at least ten years of experience in CT diagnosis. By consulting the three-section classification criteria of V3 $(13,28)$, we divided V3 into three subsegments: vertical portion originating from the foramen of $\mathrm{C} 2$, horizontal portion originating from the foramen of $\mathrm{C} 1$, and extradural portion originating from the posterior atlantooccipital membrane and ending at the site of piercing the dura. The three subsegments were referred to as V3v, V3h, and V3e, respectively (Figures 1-4). The number of branches was recorded. With regard to the arrangement of the branch of $\mathrm{V} 3$, the number 0 indicated no branches in the subsegment, and the number 1 indicated no less than one branch in the subsegment (Figure 1). There were eight kinds of arrangements of the branches altogether
$(000 ; 100 ; 110 ; 111 ; 010 ; 011 ; 001 ; 101)$. After an agreement was reached by consensus, all the data were confirmed. The reproducibility was assessed by comparing a subset of measurements made on 100 randomly selected cases. The radiologists were blinded to the measurements taken by the other radiologists. The 100 cases were reviewed by three observers, and interobserver agreement was calculated. All the data were imported into $\mathrm{R}$ statistical software, version 3.6.1, to be processed further.

\section{Results}

Six, 8 , and 7 cases were not shown in the left $\mathrm{V} 3 \mathrm{v}, \mathrm{V} 3 \mathrm{~h}$, and V3e, respectively, among the 668 cases. On the left, $25 \%$ (167/662), 20.21\% (135/660), and 6.59\% (44/661) were the frequencies of one branch in the $\mathrm{V} 3 \mathrm{v}, \mathrm{V} 3 \mathrm{~h}$, and $\mathrm{V} 3 \mathrm{e}$, 


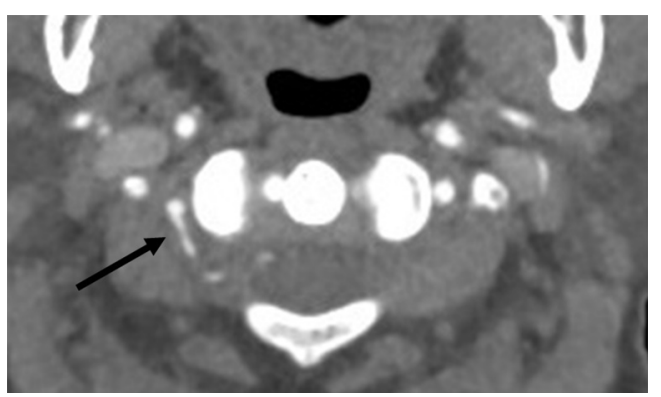

Figure 2 Illustration of the bifurcation of $\mathrm{V} 3 \mathrm{v}$ on a CTA image in a 51.3-year-old patient. One branch originated from the right $\mathrm{V} 3 \mathrm{v}$ on the axial CTA source image, and the branch coursed posteriorly (arrow).

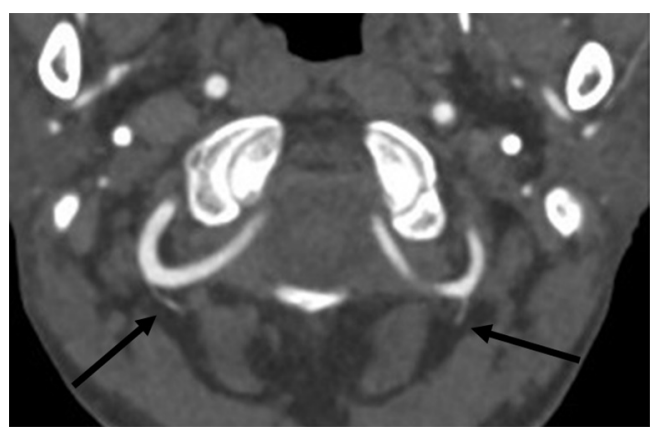

Figure 3 Illustration of the bifurcations of V3h on a CTA image in a 72.6-year-old patient. Two branches originated from the bilateral $\mathrm{V} 3 \mathrm{~h}$ and coursed normally on the axial CTA source image, and the branches coursed interior-posteriorly (arrow).

respectively, and $1.05 \%$ (7/662), $0.00 \%$ (0/660), and $0.45 \%$ (3/661) were the frequencies of two branches, respectively. Fourteen, 15, and 15 cases were not shown in the right V3v, $\mathrm{V} 3 \mathrm{~h}$, and $\mathrm{V} 3 \mathrm{e}$, respectively, among the 668 cases. On the right, $25.04 \%$ (167/654), $17.07 \%$ (114/653), and 6.44\% $(43 / 653)$ were the frequencies of one branch in the V3v, V3h, V3e, respectively, and 1.04\% (7/654), 0.3\% (2/653), and $0.15 \%(1 / 653)$ were the frequencies of two branches, respectively (Table 2).

There were no differences between the side-to-side and one branch variables according to the t-test $(\mathrm{P}=0.4341)$, and there were no differences between the side-to-side and two branch variables according to the t-test $(\mathrm{P}=0.7968)$. There were no differences between sex and one branch according to the t-test $(\mathrm{P}=0.4474)$, and there were no differences between sex and two branches according to the t-test $(\mathrm{P}=0.3593)$.
There were no differences between the side-to-side and eight arrangements (permutation of $000 ; 100 ; 110 ; 111$; 010; 011; 001; 101) according to the two-sample KS test $(\mathrm{P}=0.942)$, and there were no differences between sex and the eight arrangements according to the two-sample KS test $(\mathrm{P}=0.9973, \mathrm{P}=0.8519)$. The interobserver reliability was excellent (Spearman's ranked correlation: 0.9927).

A total of $365,115,33,7,87,7,20$, and 10 cases had the eight kinds of arrangements, the $000 ; 100 ; 110 ; 111$; 010; 011; 001; and 101 arrangements, respectively, in the left V3v, V3h, and V3e, and 373, 126, 26, 7, 76, 5, 19 , and 12 cases had these arrangements on the right. A total of $139,44,11,4,35,2,5$, and 2 cases had the eight kinds of arrangements in the left $\mathrm{V} 3 \mathrm{v}, \mathrm{V} 3 \mathrm{~h}$, and $\mathrm{V} 3 \mathrm{e}$ in the females, and 226, 71, 22, 3, 52, 5, 15, 8 cases had these arrangements in the left $\mathrm{V} 3 \mathrm{v}, \mathrm{V} 3 \mathrm{~h}$, and $\mathrm{V} 3 \mathrm{e}$ in the males. A total of 141, 54, 5, 2, 27, 2, 9, and 2 cases had the eight kinds of arrangements in the right $\mathrm{V} 3 \mathrm{v}, \mathrm{V} 3 \mathrm{~h}$, and $\mathrm{V} 3 \mathrm{e}$ in the females, and 232, 72, 21, 5, 49, 3, 10, and 10 cases had these arrangements in the right V3v, V3h, and V3e in the males (Table 2). There were no differences between sex and the left side according to the two-sample KS test $(\mathrm{P}=0.942)$, and there were no differences between sex and the right side $(\mathrm{P}=0.8519)$. According to Kendall's $W$ test, the interobserver agreement was excellent (uncorrected for ties: 0.9802, corrected for ties: 0.9939, Spearman's ranked correlation: 0.9927).

\section{Discussion}

The vertebral artery has a tortuous shape to meet the need for flexible movement and to facilitate smooth blood flow. $\mathrm{V} 3$ is anatomically defined as the vertebral artery that passes from the foramen of $\mathrm{C} 1$ to the site of the piercing dura, and it is radiologically defined as the artery passing from the foramen of $\mathrm{C} 2$ to the piercing site $(26,27)$. Considering the occipito-atlantoaxial complex is a functional complex, we adopted the latter definition. The V3 that was identified was then divided into two portions demarcated by the foramen of the $\mathrm{C} 1$ process, namely, the horizontal and vertical portions, as reported in previous studies. In this study, we divided V3 into three subsegments, namely, the V3v, V3h, and V3e subsegments $(13,29)$. V3e was the section passing from the posterior atlantooccipital membrane to the site of piercing the dura (28). The V3v was easily identified on CTA images. The starting point of V3e was defined as the point of intersection of the course of $\mathrm{V} 3$ and the superior border of $\mathrm{C} 1$ to which the posterior atlantooccipital 

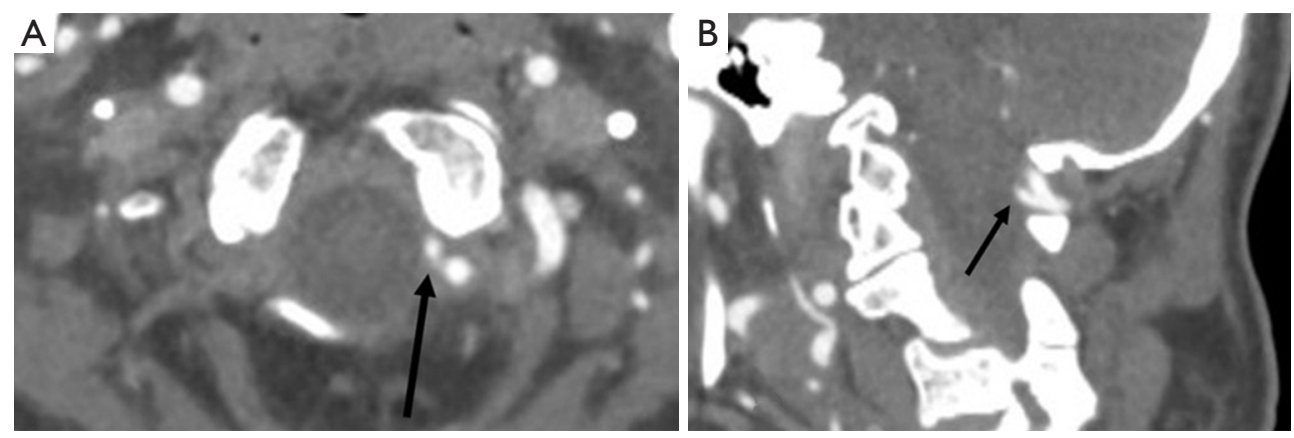

Figure 4 Illustrations of the bifurcation of V3e on CTA images in the same 46.9-year-old patient. (A) One branch sprouted interioranteriorly from the V3e and coursed normally on the left on the axial CTA source image (arrow). (B) The branch under the V3e was identified on the CTA image reformatted randomly (arrow).

Table 2 Numerical values of the three subsegmental branches on different sides

\begin{tabular}{|c|c|c|c|c|c|c|}
\hline Figure of branch & \multicolumn{3}{|c|}{ Left } & \multicolumn{3}{|c|}{ Right } \\
\hline $0(\%)$ & 488 (73.05\%) & 525 (78.59\%) & $614(91.92 \%)$ & 480 (71.86\%) & 537 (80.39\%) & $609(91.97 \%)$ \\
\hline $1(\%)$ & 167 (25.00\%) & 135 (20.21\%) & $44(6.59 \%)$ & $167(25.00 \%)$ & 114 (17.07\%) & 43 (6.44\%) \\
\hline 2 (\%) & $7(1.05 \%)$ & $0(0.00 \%)$ & $3(0.45 \%)$ & $7(1.05 \%)$ & $2(0.30 \%)$ & $1(0.15 \%)$ \\
\hline
\end{tabular}

V3v, vertical portion of V3; V3h, horizontal portion of V3; V3e, extradural portion of V3; NE, nonenhanced.

membrane attached (29). The terminal point of V3e was marked by the density difference between the cerebrospinal fluid and dura mater on CTA images. The branch arising from V3h was defined as the suboccipital artery of Salmon that supplied the neighboring muscles. The frequency of the artery of Salmon was $20 \%$ in a study of 10 cadavers and $67 \%$ a study of 15 cadavers $(26,27)$. The frequency of the artery of Salmon was $17.07-20.21 \%$ in V3h. Our results are consistent with those reported by Tubbs RS et al. Three branches arising from the $\mathrm{V} 3 \mathrm{~h}$ were discovered by dissecting cadavers (27), while no more than 2 branches were revealed in our research. The frequency of the branch was $25 \%$ in $\mathrm{V} 3 \mathrm{v}$ and less than $6 \%$ in V3e. The rate of asymmetry in the arrangements of the branches of $\mathrm{V} 3$ was $30 \%$ according to the autopsy; in other words, the rate of symmetry was $70 \%$ in the arrangements (27). In our study, all eight arrangements of branches of $\mathrm{V} 3$ were symmetric, regardless of the sex and side of the patient. The permutation of $(0,0,0)$ was the most frequently occurring permutation, followed by $(1,0,0)$, and $(0,1,1)$ was the least frequent (Table 3$)$.
It was essential for a surgeon to acquaint every patient's bifurcations of V3 on CTA before the operation. V3e is fixed by surrounding structures, and its branch has important clinical significance when an operation is conducted in the cranio-occipital region because it might cause mortal bleeding (28-30). The branch of V3 was often ignored on the CTA images by volume rendering process in postprocessing. It cannot be stressed enough that a surgeon must determine the number and locations of the branches of V3, and it is helpful for surgeons to conduct surgical planning to minimize the volume of bleeding.

Skeletal deformities of the occipito-atlantoaxial complex are usually combined with deformities of vessels, nerves, and muscles $(14,15,25)$. The anomaly rate has been reported to be much higher in people with bone deformities than in those without bone deformities (31), so subjects who had bone deformities were excluded so that we could study the frequency and arrangement of V3 in normal persons. The variation of the fenestrated vertebral artery was not assessed because it is difficult to assess for the V3, and the 
Table 3 Eight arrangements of the branches of V3 by sex and laterality

\begin{tabular}{|c|c|c|c|c|c|c|}
\hline \multirow{2}{*}{ Permutation } & \multicolumn{2}{|c|}{ Side-to-side } & \multicolumn{4}{|c|}{ Sex } \\
\hline & Left & Right & Left & Right & Left & Right \\
\hline $1(0,0,0)$ & 365 & 373 & 139 & 141 & 226 & 232 \\
\hline $2(1,0,0)$ & 115 & 126 & 44 & 54 & 71 & 72 \\
\hline $4(1,1,1)$ & 7 & 7 & 4 & 2 & 3 & 5 \\
\hline $5(0,1,0)$ & 87 & 76 & 35 & 27 & 52 & 49 \\
\hline $6(0,1,1)$ & 7 & 5 & 2 & 2 & 5 & 3 \\
\hline $7(0,0,1)$ & 20 & 19 & 5 & 9 & 15 & 10 \\
\hline
\end{tabular}

The numbers 1-8 indicate the eight kinds of arrangements.

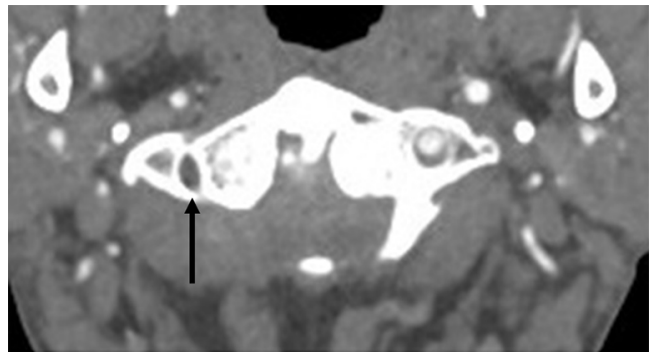

Figure 5 Illustration of the occlusion of the unilateral V3 on a CTA image in a 73.6-year-old patient. The right V3 was occluded on the axial CTA source image in the foramen of $\mathrm{C} 1$ (arrow), and the left V3 coursed normally.

other variations, such as the high-riding vertebral artery, extracranial C1/2 origin of the posterior cerebellar artery, and persistent first intersegmental artery, were included because they could be assessed. Unilateral vertebral atherosclerosis was included, which caused the asymmetric values in Tables 1 and 2 (Figure 5). Although this study had the advantages of noninvasive, in vivo, and fast imaging and had a large sample size, it had the following disadvantages compared to autopsy studies: (I) we were unable to distinguish the branches of V3 on the CTA source images from muscular, osseous radicular, meningeal branches but not for the artery of Salmon (26,32). (II) We were unable to measure the size on the source images as a result of the limited density and spatial resolution of CTA and only counted the branches whose diameters ranged between 0.5 $\mathrm{mm}$ and $1.1 \mathrm{~mm}$ according to the autopsy (26).

\section{Conclusions}

To conclude, the frequency and arrangement of the subsegmental branches of $\mathrm{V} 3$ could be viewed by the CTA source images in a large sample. The frequencies of the $\mathrm{V} 3 \mathrm{v}, \mathrm{V} 3 \mathrm{~h}$, and V3e were approximately $25 \%, 20 \%$, and $6 \%$, respectively, and the most common arrangement of $\mathrm{V} 3$ was $(0,0,0)$. This information is helpful for surgeons when performing an operation involving V3.

\section{Acknowledgments}

The authors thanks Fei Qi for his help in the statistics, and Xiaopei Guo for her help in drawing the anatomical illustration.

Funding: None.

\section{Footnote}

Conflicts of Interest: All authors have completed the ICMJE uniform disclosure form (available at http://dx.doi. org/10.21037/qims-20-725). The authors have no conflicts of interest to declare.

Ethical Statement: The retrospective study was approved by the institutional review board, and informed consent was waived.

Open Access Statement: This is an Open Access article distributed in accordance with the Creative Commons 
Attribution-NonCommercial-NoDerivs 4.0 International License (CC BY-NC-ND 4.0), which permits the noncommercial replication and distribution of the article with the strict proviso that no changes or edits are made and the original work is properly cited (including links to both the formal publication through the relevant DOI and the license). See: https://creativecommons.org/licenses/by-nc-nd/4.0/.

\section{References}

1. Inoue T, Tamura A, Saito I. Trapping and V3-radial Artery graft-V4 bypass for ruptured dissecting aneurysm of the vertebral artery. Neurosurg Focus 2015;38:Video1.

2. Kawchuk GN, Jhangri GS, Hurwitz EL, Wynd S, Haldeman S, Hill MD. The relation between the spatial distribution of vertebral artery compromise and exposure to cervical manipulation. J Neurol 2008;255:371-7.

3. Ikeda N, Hayashi H, Goto M, Satoi H, Iwasaki K, Toda H. Posterior atlantoaxial fusion as treatment option for extracranial vertebral artery dissecting aneurysm: a case report and literature review. Acta Neurochir (Wien) 2016;158:1741-4.

4. Oh CH, Ji GY, Yoon SH, Hyun D, Kim E Y, Park H, Jang AR. Delayed vertebral artery dissection after posterior cervical fusion with traumatic cervical instability: a case report. Korean J Spine 2015;12:79-83.

5. Motiei-Langroudi R, Griessenauer CJ, Alturki A, Adeeb N, Thomas AJ, Ogilvy CS. Bow Hunter's syndrome from a tortuous V1 segment vertebral artery treated with stent placement. World Neurosurg 2017;98,878.e11.

6. Benet A, Lawton MT. V3 vertebral artery to M2 middle cerebral artery bypass: 3-dimensional operative video. Oper Neurosurg (Hagerstown) 2016; 12:194.

7. Ota N, Tanikawa R, Miyama M, Miyazaki T, Kinoshita Y, Matsukawa H, Sakakibara F, Saito N, Miyata S, Noda K, Tsuboi T, Kamiyama H, Tokuda S \& Kamada K. A contralateral transcondylar fossa approach with bilateral V3 segment exposure for repairing complex vertebral artery aneurysms. World Neurosurg 2017;99:340-7.

8. Saito N, Kamiyama H, Takizawa K, Takebayashi S, Asano T, Kobayashi T, Kobayashi R, Kubota S, \& Ito Y. Usefulness of $\mathrm{V} 3$-radial artery graft-V4 bypass in bilateral fusiform aneurysms of vertebral artery: case report. Neurol Med Chir (Tokyo) 2014;54:189-91.

9. Nakaji P, Belykh E. Extracranial-intracranial bypass and the versatile vertebral artery. World Neurosurg 2014;82:1010-1.

10. Hecht N, Wessels L, Fekonja L, von Weitzel-Mudersbach
P, Vajkoczy P. Bypass strategies for common carotid artery occlusion. Acta Neurochir (Wien) 2019;161:1993-2002.

11. Mai JC, Tariq F, Kim LJ, Sekhar LN. Flow diversion radial artery bypass graft coupled with terminal basilar artery occlusion for thetreatment of complex basilar apex aneurysms: operative nuances. Neurosurgery 2013;72:ons116-26.

12. Di Somma A, Cancela Caro P, Blanco MO, Somma T, López-González A, Campero A, Emmerich J, \& MárquezRivas J. Modified "extended" suboccipital subtonsillar clipping of ruptured proximal pica aneurysm: technical note with relevant anatomical demonstration. World Neurosurg 2018;117:301-8.

13. Bruneau M, Cornelius JF, George B. Antero-lateral approach to the $\mathrm{V} 3$ segment of the vertebral artery. Neurosurgery 2006;58:ONS29-35.

14. Kim MS. Developmental anomalies of the distal vertebral artery and posterior inferior cerebellar artery: diagnosis by CT angiography and literature review. Surg Radiol Anat 2016;38:997-1006.

15. Jagetia A, Mewda T, Bishnoi I, Bhutte M, Singh H, Srivastava AK, Singh D. Understanding the course of vertebral artery at craniovertebral junction in occipital assimilation of atlas: made simplified using conventional angiography. J Neurol Surg B Skull Base 2017:78:173-8.

16. Anderson TCO, Ryo YWL, Fung MK, Man LW. MRI vessel wall imaging and treatment of an aneurysm at the atlanto-axial segment of an aberrant vertebral artery. Neurointervention 2018;13:62-5.

17. Ben Hassen W, Machet A, Edjlali-Goujon M, Legrand L, Ladoux A, Mellerio C, Bodiguel E, Gobin-Metteil MP, Trystram D, Rodriguez-Regent C, Mas JL, Plat M, Oppenheim C, Meder JF, Naggara O. Imaging of cervical artery dissection. Diagn Interv Imaging 2014;95:1151-61.

18. Desai JA, Almekhlafi MA, Hill MD, Goyal M, Eesa M. Ultrasound guided V3 segment vertebral artery direct percutaneous puncture for basilar artery mechanical thrombectomy in acute stroke: a technical report. J Neurointerv Surg 2014;6:e18.

19. Uchino A, Saito N, Kurita H. Anastomosis of the external carotid artery and the $\mathrm{V} 3$ segment of the vertebral artery (presumed persistent second cervical intersegmental artery) diagnosed by CT angiography. Surg Radiol Anat 2018;40:233-6.

20. Hong JT, Kim IS, Kim JY, Lee HJ, Kwon JY, Kim MS, Sung JH. Risk factor Analysis and decision-making of surgical strategy for $\mathrm{V} 3$ segment anomaly: significance of preoperative CT angiography for posterior $\mathrm{C} 1$ 
instrumentation. Spine J 2016;16:1055-61.

21. Paşaoğlu L. Vertebrobasilar system computed tomographic angiography in central vertigo. Medicine (Baltimore) 2017;96:e6297.

22. Kiresi D, Gumus S, Cengiz SL, Cicekcibasi A. The morphometric analysis of the V2 and V3 segments of the vertebral artery: normal values on MDCT. Comput Med Imaging Graph 2009;33:399-407.

23. Arslan D, Ozer MA, Govsa F, Kitis O. Surgicoanatomical aspect in vascular variations of the $\mathrm{V} 3$ segment of vertebral artery as a risk factor for $\mathrm{C} 1$ instrumentation. J Clin Neurosci 2019;68:243-9.

24. Spasojević G, Vujmilović S, Ponorac N, Malobabić S, Vujinović S, Đukić Macut N. Sex and level differences in the diameters of extradural segment of vertebral artery: computed tomography angiographic study. Folia Morphol (Warsz) 2019;78:494-500.

25. Zhu SW, Yang Y, Liu YG, Cao JW, Li F. Anatomical features and clinical significance of radiculomuscular artery variants involving the suboccipital segment of vertebral artery: angiographic and cadaver studies. Clin Neuroradiol 2018;28:75-80.

26. Tubbs RS, Shah NA, Sullivan BP, Marchase ND, CohenGadol AA. Surgical anatomy and quantitation of the

Cite this article as: Liu K, Liu X, Song H, Gao X, Zhang M, Qi Y. The assessment of the frequency and arrangement of the subsegmental branches of V3 using computed tomography angiography. Quant Imaging Med Surg 2021;11(4):1284-1291. doi: 10.21037/qims-20-725 branches of the V2 and V3 segments of the vertebral artery. laboratory investigation. J Neurosurg Spine 2009;11:84-7.

27. D'Antoni AV, Battaglia F, Dilandro AC, Moore GD. Anatomic study of the suboccipital artery of Salmon with surgical significance. Clin Anat 2010;23:798-802.

28. Meybodi AT, Lawton MT, Benet A. Sequential extradural release of the $\mathrm{V} 3$ vertebral artery to facilitate intradural V4 vertebral artery reanastomosis: feasibility of a novel revascularization technique. Oper Neurosurg (Hagerstown) 2017;13:345-51.

29. George B, Cornelius J: Vertebral artery: Surgical anatomy. In: Spetzler RF. (ed): Operative techniques in neurosurgery. Philadelphia, W.B. Saunders, 2001, pp 168-181.

30. Macfarlane R. Advances and technical standards in neurosurgery. J Neurol Neurosurg Psychiatry 2000;68:682.

31. Xu S, Ruan S, Song X, Yu J, Xu J, Gong R. Evaluation of vertebral artery anomaly in basilar invagination and prevention of vascular injury during surgical intervention: CTA features and analysis. Eur Spine J 2018;27:1286-94.

32. Standring S. 2008. Neck. In: Standring S, editor. Gray's Anatomy. 40th Ed. Edinburgh: Churchill Livingstone Elsevier. pp 435-466. 